\title{
An Analysis of Factors Related to the Ability of Hypoglycemic and Hyperglycemic Early Detection in patients of Diabetes Mellitus in Bima Public Hospital in 2017
}

\section{Martiningsih $^{1}$}

${ }^{1}$ Politeknik Kesehatan Mataram

\begin{tabular}{|c|c|}
\hline Article Info & Abstract \\
\hline $\begin{array}{l}\text { Article History: } \\
\text { Accepted Oct 9th } 2018 \\
\text { Key words: } \\
\text { Education } \\
\text { Detection } \\
\text { Hypoglycemia } \\
\text { Hyperglycemia }\end{array}$ & $\begin{array}{l}\text { This study aims to determine the ability of early detection, the factors that } \\
\text { are most influential and related to the ability of early detection of } \\
\text { hypoglycemia and hyperglycemia in diabetes mellitus patients in Bima } \\
\text { Public Hospital in } 2017 \text {. The method used in this research is an analytical } \\
\text { descriptive method and uses a cross-sectional approach. The population of } \\
\text { this study was all DM patients in Bima Public Hospital in } 2017 \text {. The sample } \\
\text { size was determined by purposive sampling technique, namely } 30 \text { people. } \\
\text { The study was conducted in the internal medicine room of Bima Hospital. } \\
\text { The data were retrieved by using questionnaire of Ability to Detect } \\
\text { Hypoglycemia and Hyperglycemia which has been tested for the validity } \\
\text { and reliability of the instrument with Cronbach's Alpha value of } 0.734 \text {. The } \\
\text { data analysis process was carried out by using Chi-Square test and logistic } \\
\text { regression. Results: The ability of hypoglycemia and hyperglycemia to be } \\
\text { detected in DM patients in Bima Public Hospital in } 2017 \text { was } 47 \% \text { who } \\
\text { were able and } 58 \% \text { who were not able with the average of } 42.70 \text {, with a } \\
\text { minimum-maximum value of } 34-52 \text {. The results of the multivariate test } \\
\text { revealed that the duration of DM disease had the most significant effect on } \\
\text { the ability of hypoglycemia and hyperglycemia detection (p-value = } 0.001 \text {, } \\
\text { OR } 39.429 \text { ). Discussion: Improving the quality of nursing care through self- } \\
\text { care education in the right nursing perspective with regard to the } \\
\text { characteristics of the respondents, one of them is a history of long-term DM } \\
\text { disease, can prevent acute hypoglycemia and hyperglycemia. }\end{array}$ \\
\hline
\end{tabular}

\section{PENDAHULUAN}

Diabetes Mellitus (DM) merupakan salah satu masalah kesehatan yang berdampak kompleks. Mulai dengan masalah secara fisik maupun psikososial (Yanto\&Setyawati, 2017a). Diabetes Mellitus merupakan gangguan metabolisme akibat adanya gangguan sekresi insulin atau gangguan aktifitas insulin sehingga menyebabkan terjadinya hiperglikemia dan sel tidak mendapatkan glukosa yang cukup untuk energi. Hipoglikemia dan Hiperglikemi pada pasien DM merupakan komplikasi akut DM yang dapat terjadi secara berulang dan dapat memperberat penyakit DM bahkan dapat menyebabkan kematian. Prevalensi hipoglikemi cukup tinggi, sekitar $90 \%$ pasien yang

Corresponding author: 
mendapatkan terapi insulin pernah mengalami hipoglikemia.

Tingginya prevalensi dan besarnya resiko hipoglikemi dan hiperglikemi berat berkaitan erat dengan perilaku pasien DM dalam mengelola penyakitnya, khususnya perilaku dan kemampuan dalam deteksi dini kondisi hipoglikemi. Dan hiperglikemi. Perkembangan hipoglikemi dan hiperglikemi pada keadaan yang lebih berat dapat dicegah dengan peningkatan kemampuan mengontrol glukosa darah dan deteksi dini terjadinya hipoglikemia dan hiperglikemi melalui peningkatan kemampuan deteksi dini tentang faktor resiko atau penyebab, interpretasi terhadap gejala hipoglikemia dan hiperglikemi awal sehingga komplikasi yang lebih berat dapat dicegah.

Tujuan dari penelitian ini adalah untuk menganalisis faktor yang berhubungan dengan kemampuan deteksi dini hipoglikemi dan hiperglikemi pada pasien Diabetes Melitus di RSUD Bima tahun 2017, sedangkan tujuan khususnya adalah menganalisis faktor usia, jenis kelamin, pendidikan, pekerjaan dan lama sakit DM terhadap kemampuan deteksi dini hipoglikemi dan hiperglikemi.

\section{METODE}

Penelitian ini menggunakan metode kuantitatif Deskriptif analitik dan pendekatan yang digunakan adalah cross sectional. Tempat penelitian ini adalah di RSUD Bima. Yang menjadi populasi penelitian ini adalah Pasien DM yang dirawat di Ruang Rawat Inap Penyakit Dalam RSUD Bima yang memenuhi kriteria inklusi. Sampel diambil dengan tehnik purpusive sampling, sejumlah 30 orang responden pasien DM yang memenuhi kriteria inklusi. Alat ukur yang digunakan dalam penelitian adalah kuesioner. Alat ukur terdiri dari 3 kategori, yaitu: karakteristik responden (Usia, Jenis Kelamin, pendidikan, pekerjaan dan lama sakit DM), Kemampuan deteksi hipoglikemia, dan hiperglikemia . Alat ukur untuk mengukur Kemampuan deteksi hipoglikemia telah dilakukan uji validitas dan reabilitas dengan nilai Cronbach's Alpha sebesar 0.734 yang artinya telah memenuhi syarat validitas dan reabilitas sebagai alat ukur variabel penelitian.

\section{HASIL}

Responden dalam penelitian ini berjumlah 30 pasien DM yang dirawat di RSUD Bima dengan rata-rata usia 53 tahun $(\mathrm{SD} \pm 8,175)$. Pasien DM terdiri dari 25 orang $(83,3 \%)$ perempuan dan 5 orang (16,7\%) laki-laki. Pasien DM terdiri dari 7 orang $(23,3 \%)$ tidak sekolah, 12 orang (40\%) berpendidikan sekolah Dasar, 3 orang (10\%) berpendidikan menengah dan 8 orang $(26,7 \%)$ berpendidikan perguruan tinggi. Berdasarkan status bekerja terdapat 23 orang $(76,7 \%)$ yang tidak bekerja dan 7 orang $(23,3)$ yang bekerja.

Tabel 1. Deskripsi jenis kelamin, pendidikan, pekerjaan, $\mathrm{n}=30$ Pasien DM

\begin{tabular}{lll}
\hline Karakteristik & Jumlah & $\%$ \\
\hline Jenis Kelamin & & \\
$-\quad$ Laki-laki & 5 & 16.7 \\
$-\quad$ Perempuan & 25 & 83.3 \\
\hline Pendidikan & & \\
$-\quad$ Tidak sekolah & 7 & 23.3 \\
$-\quad$ Rendah : SD & 12 & 40.0 \\
$-\quad$ Menengah : SMP, SMA & 3 & 10.0 \\
$-\quad$ Tinggi : perguruan & 8 & 26.7 \\
$\quad$ tinggi & & \\
\hline Pekerjaan & & \\
$-\quad$ Tidak Bekerja & 23 & 76.7 \\
$-\quad$ Bekerja & 7 & 23.3 \\
\hline
\end{tabular}

Tabel 2. Deskripsi Usia, Jenis Kelamin, $n=30$ Pasien DM

\begin{tabular}{lcccc}
\hline $\begin{array}{l}\text { Karakteri } \\
\text { stik }\end{array}$ & $\begin{array}{c}\text { Rata- } \\
\text { rata }\end{array}$ & S.D & Min-Max & $95 \%$ CI \\
\hline Usia & 53 & 8,175 & $36-65$ & $36.38-50.28$ \\
\hline $\begin{array}{l}\text { Lama } \\
\text { sakit DM }\end{array}$ & 1.20 & 0.847 & $1-5$ & $0.88-1.54$ \\
\hline
\end{tabular}

Berdasarkan usia Responden pasien DM yang dirawat di RSUD Bima dalam penelitian ini dengan rata-rata usia 53 
tahun (SD $\pm 8,175)$, rentang usia $36-65$ tahun.

Tabel 3. Deskripsi Kemampuan deteksi hipoglikemia dan hiperglikemia, $n=30$ Pasien DM

\begin{tabular}{|c|c|c|c|c|}
\hline Karakteristik & $\begin{array}{l}\text { Rata- } \\
\text { rata }\end{array}$ & S.D & Min-Max & $95 \% \mathrm{CI}$ \\
\hline $\begin{array}{l}\text { Kemampua } \\
\text { deteksi } \\
\text { hipoglikemia } \\
\text { dan } \\
\text { hiperglikemia }\end{array}$ & 42,70 & $\begin{array}{l}4,82 \\
9\end{array}$ & $34-52$ & $\begin{array}{l}40,90- \\
44,50\end{array}$ \\
\hline
\end{tabular}

Berdasarkan tabel 3. menunjukkan kemampuan rata-rata responden dalam melakukan deteksi hipoglikemia dan hiperglikemia adalah 42,70, dengan nilai minimal-maksimal 34-52 (95\% CI 40,90$44,50)$.

Tabel 4. Deskripsi distribusi frekuensi Kemampuan deteksi hipoglikemia dan hiperglikemia, $\mathrm{n}=30$ Pasien DM

\begin{tabular}{|c|c|c|}
\hline Karakteristik & Jumlah & $\%$ \\
\hline $\begin{array}{l}\text { Kemampua } \\
\text { hipoglikemia } \\
\text { hiperglikemia }\end{array}$ & & \\
\hline - Mampu & 14 & $47 \%$ \\
\hline - Tidak Mampu & 16 & $53 \%$ \\
\hline
\end{tabular}

Kemampuan diteksi hipoglikemia dan hiperglikemia pada pasien DM di RSUD Bima tahun 2017 adalah 14 orang ( 47\%) yang mampu melakukan deteksi dini dan yang tidak mampu sebanyak 16 orang (53\%) dengan Rata-rata skor 42,70, nilai minimal-maksimal 34-52.

Analisis multivariat menggunakan uji regresi logistik. Uji tersebut digunakan untuk memprediksi nilai variabel dependen berdasarkan variasi beberapa nilai variabel independen. Variabel yang dimasukkan dalam analisis multivariat adalah variabel yang memiliki $p$-value $<0,25$ pada analisis bivariat (Dahlan, 2016).
Tabel 5. Hubungan antara jenis kelamin, umur, pendidikan, pekerjaan, lama sakit DM dengan Kemampua deteksi hipoglikemia dan hiperglikemia

\begin{tabular}{lcc}
\hline \multicolumn{1}{c}{ Variabel } & $\begin{array}{c}\text { Koefisien } \\
\text { korelasi }\end{array}$ & $p$-value \\
\hline- Jenis Kelamin & 24.067 & 0.000 \\
- Umur & 58.300 & 0.000 \\
- Pendidikan & 10.133 & 0.017 \\
- Pekerjaan & 15.000 & 0.000 \\
- Lama mengidap & 11.200 & 0.004 \\
\hline
\end{tabular}

\begin{tabular}{lllll}
\hline \multirow{2}{*}{ Variabel } & \multirow{2}{*}{ B } & P & \multicolumn{2}{c}{ CI 95\% } \\
\cline { 5 - 6 } & & Value & Min & Max \\
\hline Umur & 19.538 & 0.998 & 0.000 & - \\
Jenis kelamin & 0.333 & 0.769 & 0.077 & 6.638 \\
Pendidikan & 0.208 & 0.817 & 0.140 & 4.702 \\
Pekerjaan & 0.767 & 0.495 & 0.051 & 4.204 \\
Lama Sakit DM & 3.674 & 0.001 & 4.109 & $\begin{array}{l}378.3 \\
8\end{array}$ \\
\hline
\end{tabular}

Faktor yang memenuhi syarat untuk dilakukan analisis multivariat terhadap Kemampuan diteksi hipoglikemia dan hiperglikemia adalah lama sakit DM. Hasil uji multivariat diketahui bahwa lama sakit DM berpengaruh signifikan terhadap Kemampuan diteksi hipoglikemia dan hiperglikemia ( $p$-value $=0,001)$.

Tabel 6. Analisis regresi logistik variabel lama sakit

\begin{tabular}{|c|c|c|c|}
\hline Variabel & B & P Value & $\begin{array}{l}C I \quad 95 \% \\
\text { min-max }\end{array}$ \\
\hline Lama Sakit DM & 3.674 & 0.001 & $\begin{array}{l}4.109- \\
378.38\end{array}$ \\
\hline
\end{tabular}

Dari analisis pemodelan akhir multivariat ternyata variabel yang berhubungan dengan kemampuan deteksi dini hipoglikemia dan hiperglikemia adalah lama sakit DM sedangkan variabel lainnya sebagai konfounding. Hasil analisis didapatkan Odd Rasio(OR) terbesar 39.429 
setelah diurut adalah variabel lama sakit, kemudian $O R$ pendidikan, $O R$ jenis kelamin, $O R$ pekerjaan dan $O R$ umur, ini berarti lama sakit DM paling dominan hubungannya dengan kemampuan deteksi dini hipoglikemia dan hiperglikemia. $O R$ dari variabel lama sakit DM adalah 39.429 artinya pasien DM dengan lama sakit lebih dari 1 tahun diprediksi 39 kali lebih mampu untuk melakukan deteksi dini hipoglikemia dan hiperglikemia dibandingkan dengan pasien DM yang mengalami sakit DM kurang dari 1 tahun setelah dikontrol variabel usia, jenis kelamin, pendidikan dan pekerjaan.

\section{PEMBAHASAN}

Faktor kondisi dasar internal yang berhubungan dengan kemampuan deteksi hipoglikemi dan hiperglikemi berdasarkan kerangka konsep dalam penelitian ini adalah umur, jenis kelamin, pendidikan, pekerjaan dan lama sakit DM. Hasil penelitian menunjukkan bahwa sebagian besar responden (70 \%) berada pada kelompok usia dewasa akhir (55-65 tahun), Umur termuda responden pasien DM adalah 35 tahun dan tertua umur 65 tahun. Rata-rata umur responden yang berkunjung di RSUD Bima adalah 63 tahun.

Umur merupakan faktor resiko kuat yang tidak dapat dimodifikasi. Faktor resiko DM sama dengan faktor resiko untuk terjadinya intoleransi glukosa yang semakin meningkat seiring dengan meningkatnya usia. Pemeriksaan gula darah harus rutin dilakukan terlebih pada usia $>45$ tahun. Gejala yang muncul akibat gangguan keseimbangan gula darah baik hipoglikemia maupun hiperglikemia pada responden dengan usia dewasa berbeda dengan gejala yang muncul pada responden lansia karena adanya perbedaan respon adrenergik yang kurang jelas muncul atau bahkan tidak ada, hal ini juga kemungkinan yang menyebabkan tingginya angka hospitasisai pada pasien DM yang dewasa akhir atau memasuki lansia dibandingkan usia dewasa awal (Beare myers,1994) disamping itu angka kejadian komplikasi akut hipoglikemia cenderung meningkat seiring bertambahnya usia (Nicola etal, 2005). Hal ini sesuai dengan penelitian yang dilakukan oleh Martha et al (2012) menyatakan bahwa penyakit DM banyak terkena pada usia $>40$ tahun. Penelitian lain dengan hasil yang sedikit berbeda adalah penelitian Supadi (2011) dalam penelitian faktorfaktor yang berhubungan dengan kemampuan pasien DM dalam deteksi hipoglikemibahwa responden dengan rentang usia 34 - 80 tahun.

Berdasarkan jenis kelamin mayoritas responden (80 \%) berjenis kelamin perempuan. bahwa rata-rata usia responden adalah 63 tahun. Menurut analisis peneliti karakteristik pasien DM yang datang berobat k RSUD Bima adalah mayoritas perempuan yang merupakan ibu rumah tangga dan datang ke RSUD dengan kondisi umum dan penyulit yang bervariasi. Penyulit DM jika tidak dikelola dengan baik akan mengakibatkan terjadinya berbagai komplikasi akut hipoglikemi maupun hiperglikemi dan resiko tinggi terjadinya komplikasi kronis pada berbagai sistem tubuh.

Lama mengidap DM kelompok Dari 30 responden rata-rata lama mengidap $\mathrm{DM}$ adalah 1.2 tahun (95\%CI 0.88-1.54), median 1 tahun dengan standar deviasi 0.847 . Berdasarkan lama sakit, mayoritas responden telah mengidap DM 1 - 3 tahun. Responden yang sakit > dari 3 tahun ada 18 respnden. Berdasarkan penelitian yang. dilakukan oleh monika, 2015 bahwa komplikasi akut maupun kronik akan semakin meningkat dengan lama sakit responden dan usaha untuk menyembuhkan kembali menjadi normal akan sangat sulit jika sudah ada komplikasi, karena kerusakan yang terjadi umumnya akan menetap jika faktor etiologi tidak diatasi dan angka kejadian komplikasi akut hipoglikemia cenderung meningkat seiring bertambahnya usia (Nicola etal, 2005). 
Secara substansi perbedaan ini sangat bermakna terhadap terjadinya peningkatan kemampuan deteksi dini hipoglemia dan hiperglikemia sehingga bisa meningkatkan selfcare pasien dan meminimalkan terjadinya komplikasi akut maupun kronis yang pada akhirnya dapat meningkatkan kualitas hidup dan self manajemen kesehatan pada pasien DM dan kemampuan dalam proses edukasi keperawatan sebagai bagian dari upaya pencegahan dan merupakan bagian yang sangat penting dari penggelolaan DM secara holistik, sebagai bagian dari 5 pilar DM yaitu aktifitas fisik, pengaturan makan, obat antihiperglikemia dan monitoring gula darah (Perkeni, 2015). Berdasarkan hasul penelitian ini dapat meningkatkan kewaspadaan perawat dan dasar dalam pemberian Program edukasi pasien DM yang harus dilakukan secara terus menerus untuk mendapatkan pengetahuan, ketrampilan dan kemampuan yang diperlukan untuk perawatan mandiri diabetes (Funnel et al, 2011). Sesuai dengan hasil review artikel (Carole at.al, 2015) bahwa edukasi selfcare DM yang baik dapat meningkatkan kemampuan kontrol gula darah pada pasien DM sehingga dapat meminimalkan perkembangan penyakit yang mengarah pada komplikasi makrovaskular dan mikrovaskular.

Penderita DM dapat hidup nyaman apabila dapat mengontrol kadar gula darah pada level yang normal. Komplikasi awal dari tidak terkontrolnya kadar gula darah adalah kondisi hipoglikemi dan hiperglikemi. Peran perawat sangat kompleks dalam memberikan pendidikan kesehatan kepada pasien karena perawat mendampingi pasien selama 24 jam dalam perawatan di rumah sakit dan edukasi tersebut menjadi bekal dalam pengelolaan DM di rumah sehingga dapat meningkatkan manajemen DM secara mandiri. Penelitian Maharani (2014) bahwa pendidikan kesehatan efektif terhadap peningkatan pengetahuan mendeteksi tanda dan gejala hiperglikemia dan hipoglikemia pada pasien DM. Pelibatan keluarga dalam penatalaksanaan diabetes mellitus di rumah sangat dibutuhkan dan akan memberikan dampak yang signifikan terhadap pengelolaan penyakit diabetes mellitus (Yanto\&Setyawati, 2017b).

\section{SIMPULAN}

Mayoritas responden adalah jenis kelamin perempuan $(80.0 \%)$ responden, Tingkat pendidikan terbanyak pada pendidikan dasar dengan pekerjaan yang terbanyak adalah responden yang tidak bekerja. Sedangkan berdasarkan usia mayoritas responden pada kelompok usia dewasa akhir $>55$ tahun dengan lama sakit > dari satu tahun. Karakteristik responden(umur,jeniskelamin, pendidikan, pekerjaandan lama sakit DM) memiliki hubungan dengan kemampuan deteksi dini hipoglikemia dan hiperglikemia. Dari analisis pemodelan akhir multivariat variabel yang berhubungan dengan kemampuan deteksi dini hipoglikemia dan hiperglikemia adalah lama sakit.

\section{REFERENSI}

Afaf, at al, (2015). Reasons for hospitalization in adults with diabetes in kuwait. International jurnal of diabetes mellitus 3, 65-69. www. Sciencedirect.com

AdamAS,at all. (2003).Barriers toself monitoring of blood glucoseamongadulswithdiabetesinanHMO:Cro ss Sectional Study,BioMedCentral.

Arikunto, S. (2002). Prosedur penelitian suatu pendekatan praktek edisi revisi VI. Jakarta :Rinake Cipta.

Aru W Sudoyo. (2006). Ilmu Penyakit Dalam vol 3. Jakarta : Pusat Penerbitan IPD Fakultas Kedokteran Umum Indonesia

Beare G, Myers J.(1994). Principles and practice of adult health nursing, 2nd ed.Mosby

Bonnie Wakefield. (2016). Telemonitoring improves diabetes control, but more work is needed.http://www.sciencedirect.com/scienc e/journal

Carole at al.(2015). Diabetes self management education for adult with type 2 DM: a sistematic riview of the effect on glycemic 
control. Patient educatioj dan conseling. www. Elsevier.com

Denyes M, Orem D \& Sozwiss G (2001). Self-Care: a foundational science. Nursing science quarterly $14,45-54$.

Funnell, M., Brown, T.,at al (2012). National Standart for Diabetes Self-managemen Education Diabetes Care.

Hidayat, A. Aziz Alimul. (2007). Riset Keperawatan dan Teknik Penulisan Ilmiah. Jakarta : Salemba Medika

HudakCM

\&GalloBM.

(2005).Criticalcarenursing:AHolistikApproach , 6th edition,Philadelphia, LippincottCompany.

International diabetes federation, (2009). Self monitoring of blood glucosa in type $2 \mathrm{DM}$.

Martha, et al. (2012). Analisi faktor-Faktor resiko yang Berhubungan dengan Penyakit DM pada Perusahaan X. Tesis tidak dipublikasikan. Universitas Indonesia.

Maharani (2014). Efektifitas pendidikan kesehatan terhadap peningkatan pengetahuan mendeteksi tanda dan gejala hiperglikemi dan hipoglikemia pada pasien DM di RS TNI AU Lanud Adi Soemarmo Colomadu Karanganyar. JIKI Vol 7, No 2

Monika et al.(2015). Hubungan kadar gula darah tidak terkontrol dan lama menderita DM dengan fungsi kognitif pada subyek DM type 2

Nicola, et al, (2005). Hypoglycemia in type 2 Diabetes. Diabetes Care, volume 28, No.12.
Rayyapa, et al, (1999). The impact of socio-economic factors on diabetes care. Int.diab.dev.countries, vol 19.

Orem, D. E. (2001). Nursing: Concepts of practice. (6th ed.). St. Louis: Mosby. NursingReference Center. http://web.ebscohost.com

Pusat Data dan Informasi Kemenkes RI. (2014). Situasi dan Analisis DM.

Sinta apriliani,dkk. (2013)Pengaruh Edukasi Dengan Metode Kelompok terhadap perawatan diri pasien DM tipe 2. Unpad Bandung

Smeltzer C. Suzanne, Brunner \& Suddarth. 2002. Buku Ajar Keperawatan Medikal Bedah. EGC : Jakarta.

Supadi, (2011). Faktor-faktor yang berhubungan dengan kemampuan pasien DM dalam mendeteksi episode hipoglikemi di RSUD Margono Soekarjo Purwokerto.

Soegondo. 2007. Diabetes Melitus, Penatalaksanaan Terpadu. Balai Penerbitan FKUI, Jakarta.

Tjokroprawiro, Askandar. 2009. Diabetes Mellitus Klasifikasi Diagnosis dan Terapi, Edisi Ketiga PT Gramedia Pustaka Utama : Jakarta

Tri Sunaryo (2008). Faktor-faktor yang berpengaruh terhadap kemampuan deteksi dini hipoglikemi. Tesis UI. Tidak dipublikasikan.

Yanto, A., \& Setyawati, D. (2017a). Psychosocial Needs of Type-2 Diabetes Mellitus Patients in Semarang City. Health Notions, 1(3), 189-191.

Yanto, A., \& Setyawati, D. (2017b). Dukungan Keluarga Pada Pasien Diabetes Mellitus Tipe 2 Di Kota Semarang. Paper presented at the PROSIDING SEMINAR NASIONAL \& INTERNASIONAL. 